\title{
PARA UN CORPUS DE LAS PIEDRAS DURAS EN ESPAÑA. ALGUNAS PRECISIONES
}

\author{
POR \\ MARÍA PAZ AGUILÓ ALONSO \\ CSIC
}

\begin{abstract}
A través de la publicación de una mesa romana inédita, conservada en la granadina Abadía del Sacromonte, se revisan las posibles procedencias de otros tableros así como las vicisitudes del tráfico artístico de estos objetos y su utilización como regalo diplomático a finales del siglo xvI.

Palabras clave: Mobiliario. Piedras Duras. Roma. 1570-1590. Tráfico artístico. Regalo diplomático.

Through the presentation of an unpublished Roman pietre dure table preserved in the Abadía del Sacromonte (Granada), the possible provenances of other similar tables are revised, as is the art trade in these objects and their utilization as diplomatic gifts during the late sixteenth century.

Key words: Furniture. Pietre dure. Rome. 1570-1590. Art trade. Diplomatic gift.
\end{abstract}

En ocasiones anteriores hemos abordado el tema a propósito de las mesas del Museo del Prado, en relación con el mobiliario y con la decoración de los palacios desde finales del siglo $\mathrm{XVI}$, a través de las piezas conservadas en la actualidad, de las fuentes literarias y de la documentación que se desprende de los inventarios reales ${ }^{1}$. Muchas de estas piezas fueron estudiadas con más detenimiento por Alvar Gonzalez Palacios y Annamaria Giusti, poniéndolas en relación con otras conservadas en otras colecciones de todo el mundo, estudios que al fin culminan en la exposición celebrada en el Museo del Prado recientemente, en la que, a través de la documentación, Gonzalez Palacios ha resuelto algunos de los enigmas que ciertas piezas presentaban ${ }^{2}$. Tal es el caso del tablero de una de las dos grandes apoyadas en cuatro leones, que conserva el propio museo, en el que se representan armaduras y turcos encadenados, identificándolo como uno de los que pasó a las colecciones reales procedente de la almoneda de Don Rodrigo Calderón (fig. 1).

Durante años se había relacionado con un posible regalo de Pío V a don Juan de Austria, descartandose por la imposiblidad de combinar las fechas con el estilo ${ }^{3}$, aunque persiste el

1 Aguiló, M. ${ }^{a}$ P.: «Las colección de mesas de Piedras Duras del Museo del Prado». Antiqvaria 1996, n. ${ }^{\circ}$ 142, pp. 28-34, y Aguiló: El mueble en España. Siglos xvı y xvII. Madrid. Ed. CSIC, y Antiqvaria. 1993, pp. 133-135.

${ }^{2}$ Gonzalez Palacios, Alvar: Las colecciones reales españolas de mosaicos y piedras duras. Museo Nacional del Prado. 2001.

${ }^{3}$ Ibidem. Catálogo n. ${ }^{\circ}$, p. 73 


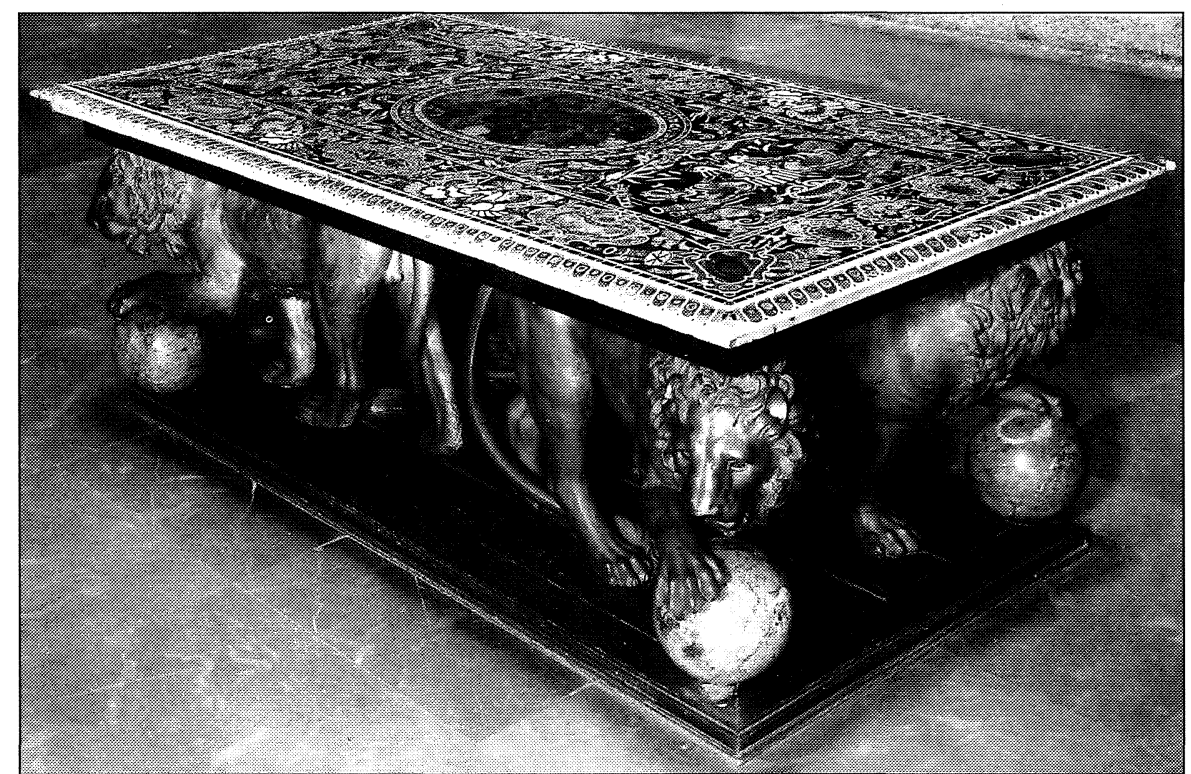

Fig. 1. Mesa de mármoles y piedras duras. Roma. Último cuarto del siglo XVI. Madrid. Museo del Prado.

enigma de su primer destinatario, ya que, en la oscura historia del proceso de Rodrigo Calderón y de su apropiación por la fuerza de esta mesa en Roma, se nombra insistentemente a una «persona eclesiástica». Esta afirmación no resulta extraña, ya que como constató Jestaz la mayoría de las expediciones de mármoles romanos pasaban por manos de embajadores o cardenales y es a través de las valijas diplomáticas como salían de Roma ${ }^{4}$. Dentro de las conjeturas sobre su primer destino, podría igualmente apuntarse una relación posible con la figura de Alejandro Farnesio, partiendo del estudio de Leuchner sobre la rápida difusión a través del grabado de obras escultóricas contemporáneas. Tal fue el caso del grabado realizado por Villamena sobre la escultura de la Apoteosis de Alejandro Farnesio de Moschino, que se erigía en 1600 en el romano palacio Farnesio, en la que se representa al duque como jefe militar con la religión falsa a sus pies ${ }^{5}$. Entre otras obras cercanas, cita la estampa reutilizada por Philip Galle del Monumento al Duque de Alba, erigido por Jonghelinck en el puerto de Amberes hacia 1570, pero tomando ambas como referencia la gran obra de Leoni Carlos $V$ y el furor. En este caso Leuchner cita solo como referencia sobre la figura caída, cita la Alegoria de Lepanto de Tiziano (Prado) (fig. 2), que representa a Felipe II como vencedor de los turcos, según la idea del propio rey ${ }^{6}$.

Sin embargo, esta referencia es mucho más clara en la obra que tratamos. Tiziano pintó al turco caído, vencido y encadenado, pero no bajo el pie del vencedor, sino a un lado, en una postura muy cercana a la de las cuatro figuras idénticas que aparecen sobre el tablero de la mesa del Prado. Los turcos, con inconfundibles rostros de dolor y vistiendo turbante y armadura, no están disparando cañones, como anotaban los inventarios, sino junto a ellos, encadenados y vencidos (fig. 3). Es seguro que la presencia de éstos en el tablero fue la causa de su errónea atribución a D. Juan de Austria. A la vista del cuadro y teniendo en cuenta la relevante participación del duque de Parma en Lepanto, es posible que se quisiera de algún modo poner

\footnotetext{
${ }^{4}$ Jestaz, Bertrand: «L'exportation de marbles de Roma de 1535 á $1571 »$ en Mélanges d'archéologie et d'histoire de l'Ecole Francaise de Roma. LXXV. 1963, pp. 413-466.

${ }^{5}$ Leuchner, Eckhard: «Francesco Villamena's Apotheosis of Alexandre Farnese and engraved reproductions of contemporary sculpture around 1600» Simiolus. Netherlands quaterly for the History of Art. Vol. 27. 1999. N. ${ }^{\circ}$ 3, pp. 144-167.

${ }^{6}$ Vease M. Tanner: The last descendant of Aeneas: the Hapsburgs and the mythic image of the emperor. New Haven \& London, 1993, pp. 216-217.
} 

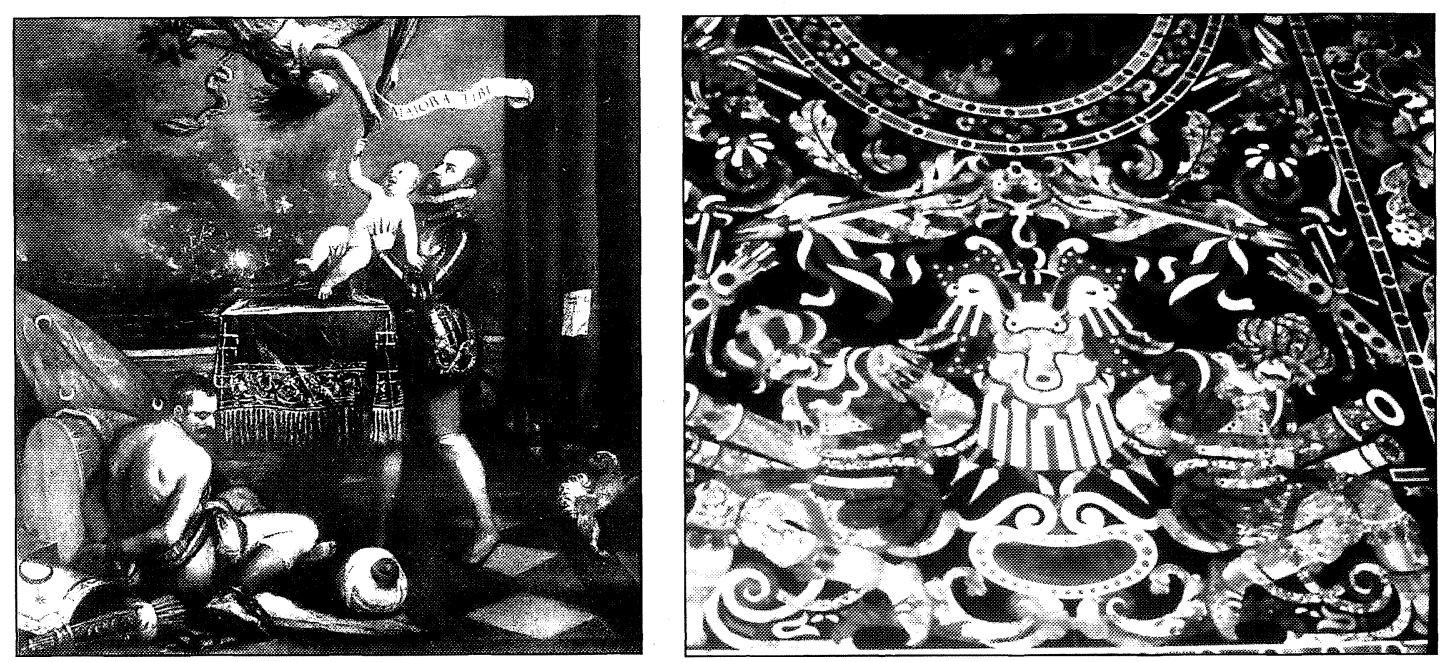

Fig. 2. Tiziano. Felipe II presentando al infante Don Fernando. Madrid. Museo del Prado.

Fig. 3. Detalle de la Mesa de mármoles y piedras duras. Madrid. Museo del Prado.

de relieve la estrecha relación entre Felipe II y Alejandro Farnesio, si bien somos conscientes de la no existencia de prueba documental conocida sobre la pertenencia del tablero a este último. Los inventarios romanos de los Farnesio son posteriores a la forzada adquisición de la pieza por Rodrigo Calderón y aunque en en ellos se constatan más de doce tableros, sin contar el más afamado, la gran mesa, con pies también de mármol, cuyo diseño se ha atribuido a Vignola (Metropolitan Museum) y que ocupaba el lugar del salón central en el que más tarde se colocaría la escultura de Moschino ${ }^{7}$.

Tableros de mármoles y piedras duras, rectangulares o cuadrados, grandes y pequeños, conformaron también la colección real. Aunque los inventarios de Felipe II son muy parcos en este tipo de piezas, no llegando las recogidas a media docena ${ }^{8}$, otros documentos demuestran que tenía otras importantes, como el tablero enviado por el cardenal Alessandrino, tambien en el Museo del Prado. El momento de mayor auge de este tipo de decoración fue el primer tercio del siglo XVII. Su adquisición se llevaba a cabo mediante compras en almonedas o se recibian en el intenso tráfico artístico que conllevaban los regalos diplomáticos. Posiblemente muchos de los tableros llegados de Italia, vía Genova, carecían de pies, pues generalmente no aparecen descritos, excepto en las piezas muy grandes, como la citada más arriba de Rodrigo Calderón, que sí aparece siempre descrita so-

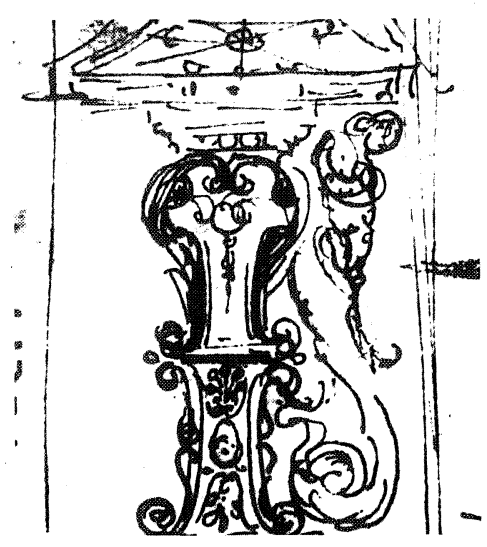

Fig. 4. Pie para tableros de commesso. Diseño de G.B.da Tivoli. Roma. Biblioteca Vaticana. bre pies de mármol. Estos fueron sustituidos por los leones procedentes del destruido Alcázar de Madrid después de 1750. Aunque se conocen dibujos para pies ya desde 1554, como los realizados por Giovanni Colonna da Tivoli ${ }^{9}$ (fig. 4 ), los inventa-

\footnotetext{
7 B. Jestaz: «La decor mobilier, la sculpure moderne et les objets d'art» en Le Palais Farnese. Roma, 1981, pp. 388408.

8 Sánchez Cantón: Bienes muebles... en el «Cargo de mesas y bancos» n. ${ }^{\circ} 4.542-4.545 ; 4.554$.

9 Cod. Lat. Vat. 7721, publicados por Tuena: «Appunti per la Storia del commesso romano», Antología di Belle Arti 1988, 33-34, pp. 54-69, recogidos por Aguiló: «Mesas de piedras duras del Museo del Prado», Antiqvaria 1996, n. ${ }^{\circ} 142$, p. 31.
} 
rios citan pies a veces de mármol, pero casi siempre lo son de madera. La fragilidad en ambos casos obligaba a su reparación o cambio, realizado ya en su lugar de destino, España, y según las modas imperantes, prácticamente casi siempre en madera, si el peso lo permitía, figurando en los inventarios generalmente como tallados y dorados. Una noticia de este quehacer viene dada por el encargo a Juan Gomez de Mora, en fechas cercanas a la visita del príncipe de Gales, de dar las trazas «de los pies para los tableros de diferentes jaspes que se habían de poner en las bóvedas bajo el Consejo Real arrimadas a la torre Bahona» ${ }^{10}$. Cincuenta años más tarde, en la Audiencia del Gran Duque de Moscovia que tuvo lugar en el Alcázar en 1687, aparece descrito otro tipo de pie como el del «bufete cuadrado, situado en el centro del Salón de Espejos, guarnecido de labores y flores compuestas y aplicadas de piedras de ágatas de las colores que requieren las flores que de ella estan compuestas (por cierto obra de grande primor y trabajo). El pie de dicho bufete es de ébano y caoba, embutido en sus planicies de piedras de pórfido y ágata de diversos colores» ${ }^{11}$. De igual modo, al describir la «Pieza Nueva sobre el Zaguán» se cita «otro [bufete] de follajes a la romana sobre mármol negro, con una orla y tarjeta embutidos sobre el brocatel con sus pies dorados a listas y ralladas» ${ }^{12}$.

Damos aquí a conocer un tablero distinto por su hechura y tamaño, que se conserva en la sacristía de la granadina abadía del Sacromonte ${ }^{13}$ (fig. 5).

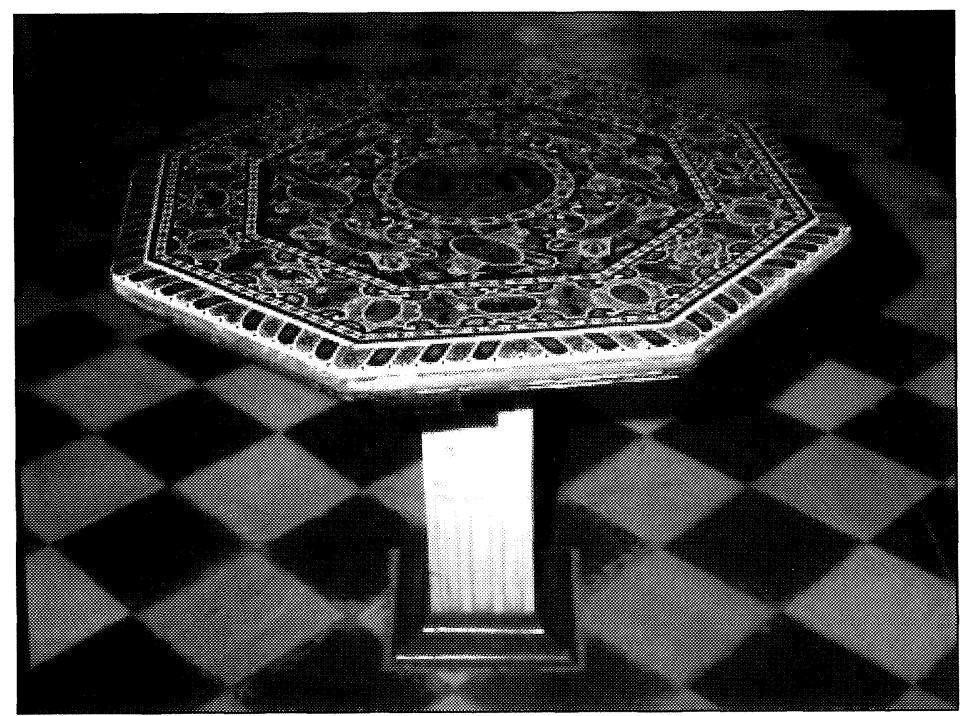

Fig. 5 . Mesa de commesso. Roma .Ca.590. Granada. Abadía del Sacromonte. Sacristía.

De forma octogonal, hoy sobre un pedestal acanalado de mármol blanco, su superficie está ornada de calizas de diferentes colores sobre un fondo de mármol blanco. El centro lo ocupa un círculo de alabastro tartaruga delimitado por un collar de óvalos de lapislazuli bordeado de giallo antico, encadenados mediante mármol blanco y rellenando los huecos piezas de rosso antico. En torno a este se disponen peltae $\mathrm{y}$ escudos ovalados enmarcados en blanco, dispuestos sobre trofeos militares: carcajs, cañones, lanzas y banderolas, todo ello sobre fondo negro, utilizandose los mármoles giallo antico, brocatello, y rosso antico. Sobre los peltae aparecen pétalos abiertos en forma de palmeta y sobre los escudos lirios en rosso y nero con los centros en lapislázuli. Otros dos collares de óvalos y puntos esta vez predominando el rosso y el brocatel sobre fondo blanco, delimitan la cenefa exterior con cartelas en las que sendos lirios es-

\footnotetext{
10 A.G.S. CMC 3. época, Leg. 784, documento recogido por Sáenz de Miera en El Alcázar de Madrid, 1994, p. 276.

$"$ Cfr. «Fuentes escritas» en El Alcázar de Madrid, 1994, ’p. 502. La descripción, al referirse a «piedras de ágatas» corresponde sin duda a la otra mesa, hoy también sobre leones, del Museo del Prado, documentada recientemente como la enviada a Felipe II por el cardenal Alessandrino G. Palacios: Las colecciones..., cat. n. ${ }^{\circ}$, aunque no es cuadrada, sino rectangular y muy grande. No puede tratarse de otra por ser la más preciada de la colección y ocupar siempre el lugar preferente del Alcázar.

12 Inventario del Alcazar de Madrid, 1636 A.G.S. Sección Administrativa 768.

13 Cuyo conocimiento debo a nuestro tristemente desaparecido amigo Juan Miguel Serrera.
}

$A E A, \mathrm{LXXV}, 2002,299$, pp. 255 a 267 
tilizados en rosso y giallo antico y nero di Belgica flanquean ovalos de mármol de Aquitania y a su vez conforman escudos de brocatel en los ángulos con óvalos de alabastro en su interior. El borde exterior formado por una amplia moldura curvada en pecho de paloma decorada con lengüetas alternando bandas de brocatel y nero centradas con pequeños círculos, bordeados alternativamente de rosso antico y de negro, rematados en los extremos con pequeños puntos.

Por los tipos de marmoles utilizados, la tonalidad general y el diseño, este tablero, no parece presentar muchas dudas para su atribución a talleres romanos de finales del siglo XVI. El Museo del Prado conserva una, no octogonal, sino cuadrada (inv. O-469), descrita en los inventarios desde 1686, que sigue un esquema repetido en otras, clasificadas por Gonzalez Palacios como romanas, realizadas a partir de 1563 . Todas ellas tienen en común la incorporación de una pieza central grande, generalmente de alabastro, la mayoría de las cuales presentan sus bordes facetados. Todas ellas tienen en común también, la utilización de collarinos, que delimitan las diferentes zonas, elemento característico de la producción romana, como lo son también los motivos naturales estilizados, como los lirios, que comienzan a acompañar a los elementos decorativos abstractos, y más propios de Roma que de Florencia. Tampoco es usual la utilización de los collarinos en obras florentinas, incluso en las más influidas por Roma en las que aparecen panoplias y armas, como la de los duques de Osuna (Museo del Prado), la de Villa Petraia, en Florencia, o la del Museo de la Sinagoga de Roma ${ }^{14}$, pues en las obras florentinas se observan mayor cantidad de piedras silíceas, mientras que tanto en la que comentamos, como en la de Rodrigo Calderón, citada más arriba y otras relacionadas con ella, apenas hay unas piezas de cuarzo y de lapislázuli, siendo el mármol el material preponderante.

Hasta hoy solamente se conocían tres tableros octogonales con características similares. Uno de ellos bastante igual, tanto en dimensiones $(120 \mathrm{~cm}$.) como en

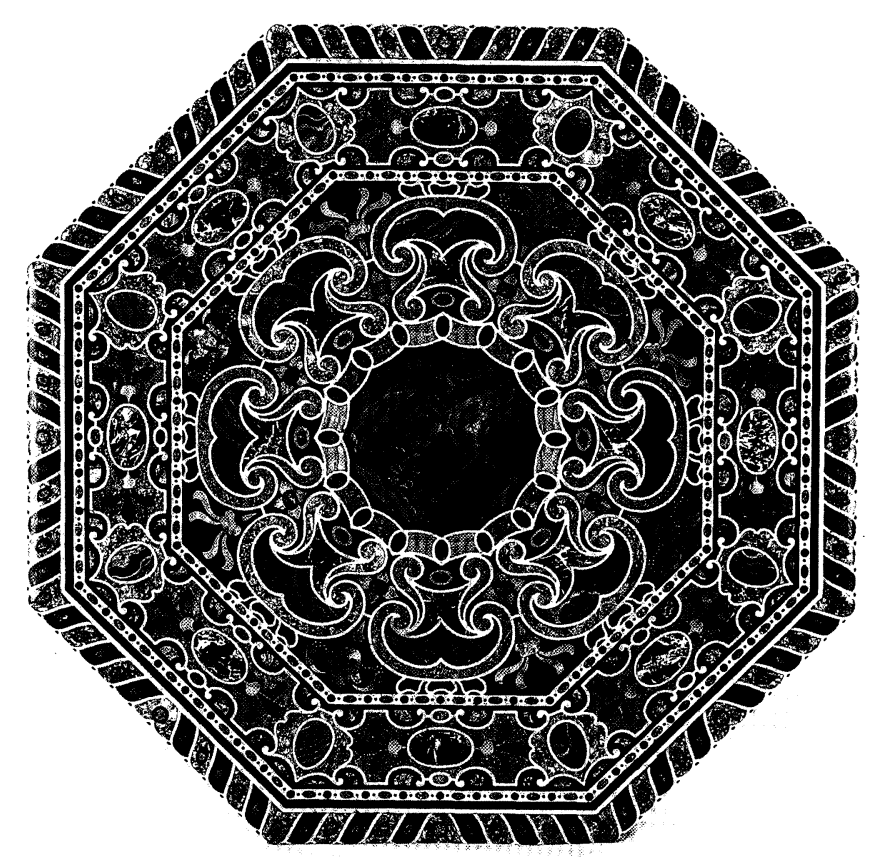

Fig. 6. Tablero de commesso. Roma. Palacio del Quirinal. concepto decorativo es el que se conserva en el palacio del Quirinal en Roma (fig. 6), al que Gonzalez Palacios ha atribuido una filiación romana ${ }^{15}$, comparándolo con la mesa Farnesio del Metropolitan Museum y cuyo diseño ha sido atribuido a Vasari, si bien, al carecer de documentación romana precisa, deja abierta la posibilidad de trabajos similares florentinos. Un ejemplo claro de esta conexión es el hecho de que Niccolo Gaddi, uno de los impulsores de la tarsia lítica en la ciudad del Arno, estuvo en estrecho contacto con Giovanni Antonio Dosio,

\footnotetext{
14 Giusti. 1992, fig. 33, y en otra sin localización reprodudida en la lám. 10.

15 Ya en Splendori di pietre dure. Catalogo de la mostra. Firenze, 1988, pp. 49 y 51 y en el «Taccuino di pietre dure. Scheda IV. Un tavolo ottogonale al Quirinale» en Il Gusto dei Principi, 1993, 384 figs., 696,697.
} 


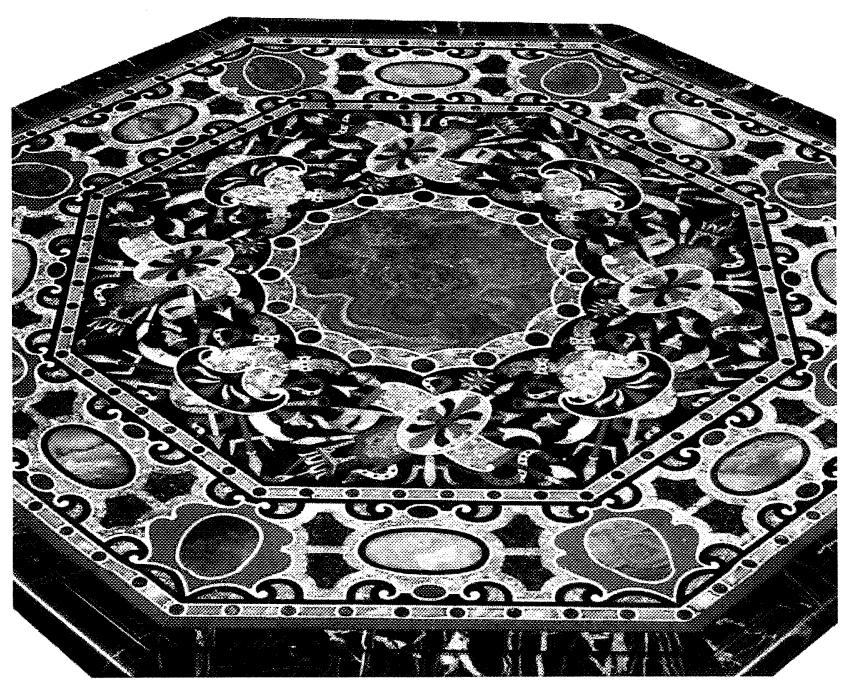

Fig. 7. Tablero de commesso. Col. Lord Arundel. Arundel Castle. Gran Bretaña. arquitecto florentino que trabajó en Roma hasta 1566 , donde pudo haber visto la mesa Farnesio. De Dosio se conservan unos diseños para mesas en el Gabinete de Estampas de los Uffizi, uno de los cuales es muy semejante al tablero del Quirinal. G. Palacios llama ya la atención sobre el borde festoneado haciendo ver las diferencias con la mesa Farnesio y sobre la pieza central, un disco de alabastro nuvolato di Palombara cortado en 16 caras, solución existente en otra hoy en el Museo del Louvre que perteneció al cardenal Richelieu con 24 caras. En cambio este campo es practicamente idéntico al segundo tablero, el conservado en Arundel Cas-

tle (fig. 7), junto con otro rectangular, los dos insertos en un marco de mármol negro de Aquitania, fechadas por Jervis en el siglo XVII, siendo ambos también de clara filiación romana ${ }^{16}$.

La tercera, aparecida en

la Galeria Kugel de París, conserva un pie con aguilas redoradas, plausiblemente las originales, cuyo diseño de sobria elegancia se relaciona con la misma idea de Giovanni Antonio Dosio. Esta mesa por su parte, cuenta un documento histórico ya que es sin duda la que aparece en un cuadro atribuido a Giovanni Battista Peggi, Il Dogo Agostino Doria e la Famiglia (1601-1603), cuadro de localización hoy desconocida y además está descrita en el testamento de Giuseppe Doria en 1816 , como la que lleva una gran pieza octogonal de alabastro cotognino ${ }^{17}$, que impide la inclusión de una segunda cenefa como en las otras y por tanto no incluye el collarino (fig. 8).

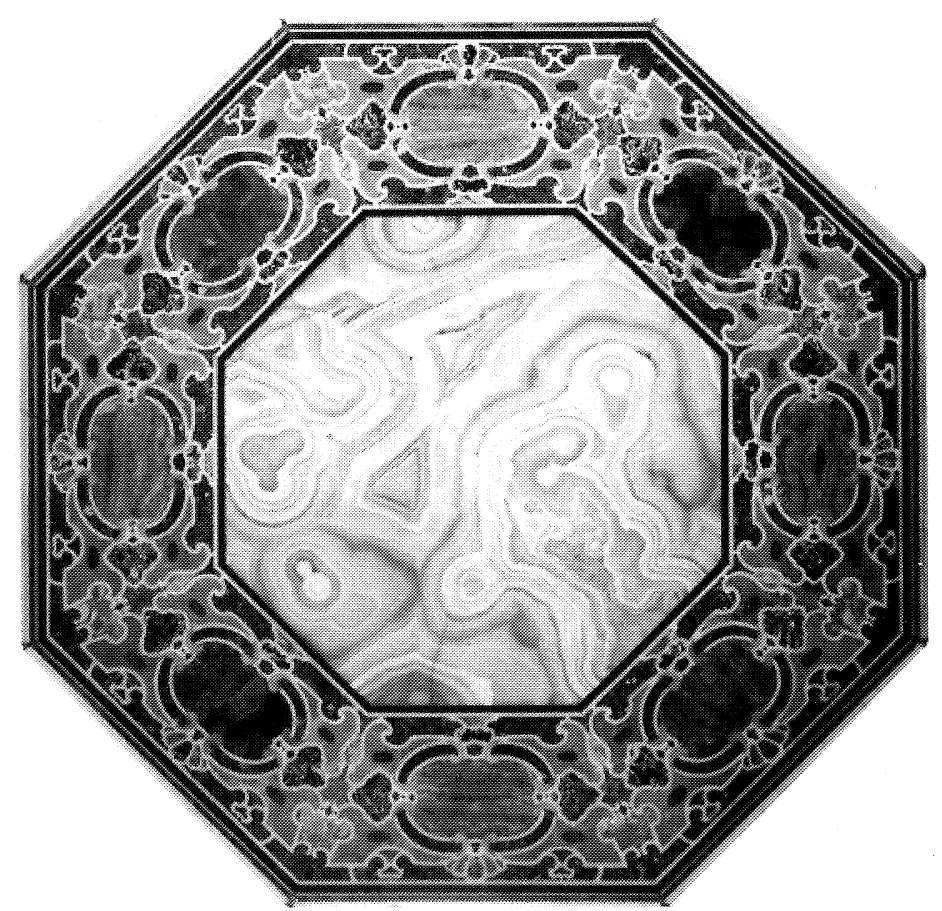

Fig. 8. Tablero de commesso, que perteneció al Dogo Agostino Doria. Ca. 1600. Colección particular.

16 Jervis, Simon: The Connoisseur n. ${ }^{\circ} 197$ (1), 1978, pp. 206-209. La rectangular, similar en su cenefa externa de cartelas, lleva en su interior idénticos lazos y motivos vegetales a otra del Prado citada más arriba con los pies «a listas y rallados» $(\mathrm{O}-470)$. 


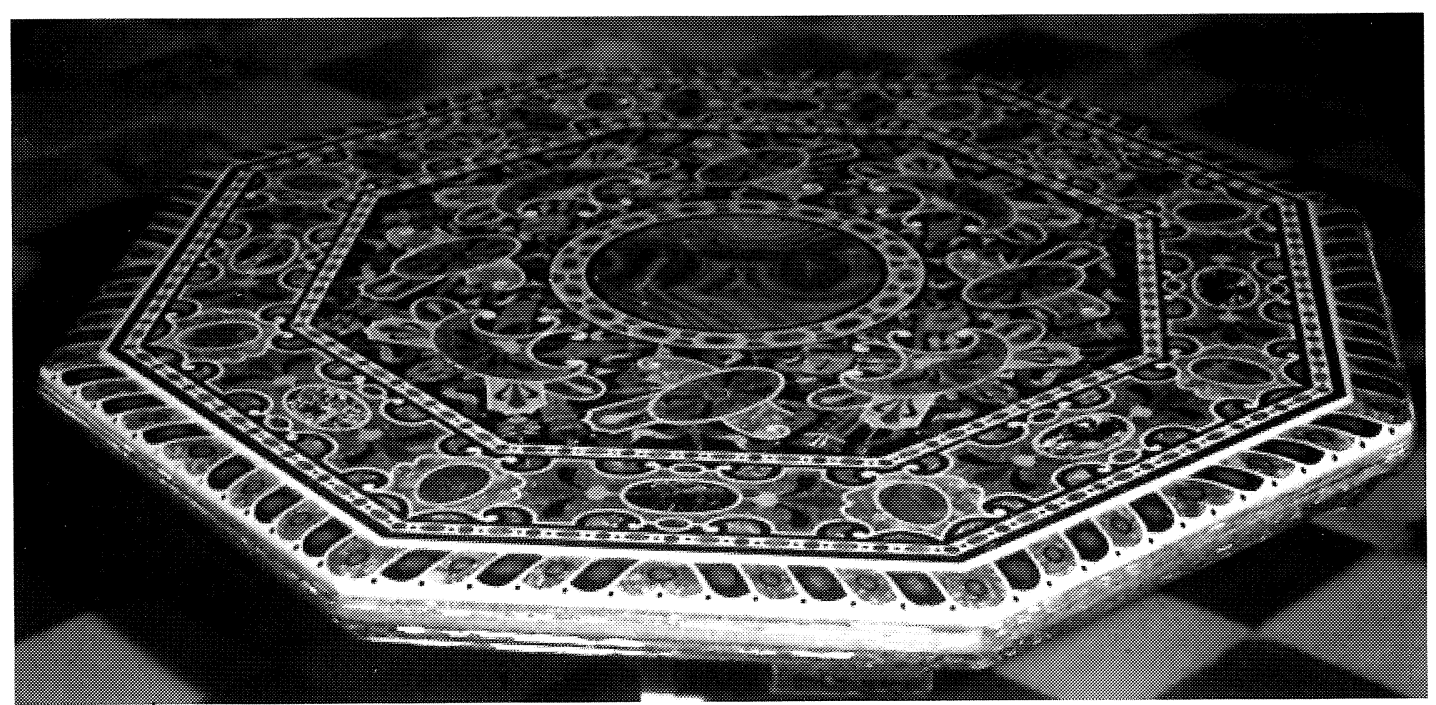

Fig. 9. Detalle del commesso. Granada Abadía del Sacromonte.

En cambio, en el bufete granadino (fig. 9), tanto el borde exterior con lengüetas, la cenefa con las cartelas y los collarinos son exactos al del Quirinal. Varía el registro interior, animado aquí por los motivos de trofeo, más floral y encadenado en aquella y la pieza central, que en la conservada en la abadía granadina es circular, pero del mismo tipo de alabastro. El modo de realizar los tableros, embutiéndolos en un cerco de mármol, con decoración de lengüetas, no se encuentra en la de la colección inglesa y sí en cambio, además de en estos dos bufetes octogonales, Sacromonte y Quirinal, en la mesa clasificada como perteneciente a D. Rodrigo Calderón del Museo del Prado, citada más arriba y en otra, muy parecida a esta última, recientemente adquirida por el Museo Nacional de Artes Decorativas de Madrid (fig. 10) ${ }^{18}$, así como en la del Museo Nacional de Arte Antiga de Lisboa y en la del Museo J. Paul Getty ${ }^{19}$. Todas ellas, excepto la del Quirinal, tienen también en común el empleo de motivos no solo geométricos, sino de flores estilizadas, panoplias y trofeos. A las tres últimas citadas G. Palacios en sus reflexiones realizadas a propósito de la exposición del Prado, las clasifica como estrictamente con-

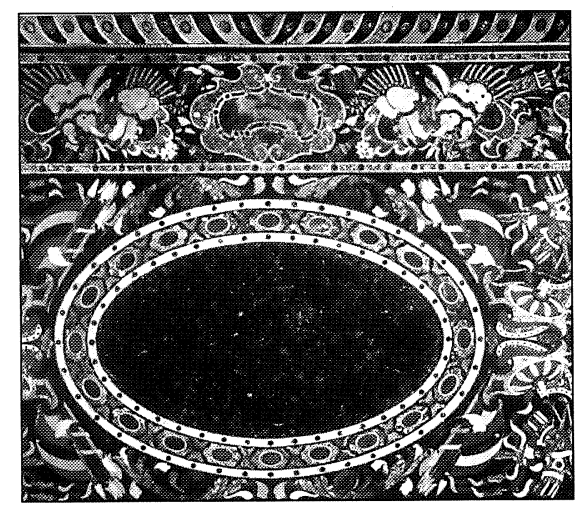

Fig. 10. Detalle de commesso romano. Madrid. Museo Nacional de Artes Decorativas. temporáneas y posiblemente de un mismo taller romano, o al menos con la intervención de un mismo diseñador, ya que las notables semejanzas resaltadas no pueden ser fruto de la casualidad, aunque sí advierte que hay diferencias en tiempo entre ellas ${ }^{20}$.

En sus reflexiones acerca de la decoración del Palacio Farnesio, Jestaz consideraba, con acierto, que la tendencia del mobiliario en el Renacimiento es la decoración de marquetería, es decir la decoración sistemática de materiales y colores, de la que las mesas de mármoles son

\footnotetext{
17 González Palacios, A.: «Tarsie litiche» en Il Mobile en Liguria. 1996, pp. 48-50, figs. 60-62.

18 Inventario n. ${ }^{\circ}$ 19.571. Adquirida en Sotheby's N. York el 5 de noviembre de 1998.

${ }^{19}$ Giusti: Op. cit., fig. 13.

${ }_{20}$ Mosaicos... 2001, p. 52.
} 
el máximo exponente ${ }^{21}$. El tipo romano es más simple y vigoroso que el popularizado en el siglo XVII por el Opificio florentino, respondiendo tan bien al gusto de los Farnesio que se reencuentra en las marqueterías de marmol que decoran por ejemplo la iglesia del Gesú.

La exportación de mármoles romanos labrados y sin labrar a mediados del siglo xvI a toda Italia y fuera de ella, llegó a proporciones tan inquietantes que indujo a Paulo III a prohibir este comercio, incluyendo no solo a los mármoles antiguos sino también a las manufacturas modernas realizadas con piedras antiguas. Entre los permisos conseguidos figuraba el de Pietro de Avila para exportar tabulam lapideam ex diversorum colorum lapidibu compacta ${ }^{22}$. Hay que advertir que la moda de estos tavolini preciosos, denominados en los inventarios españoles como bufetes o bufetillos ochavados, realizados en piedras antiguas, generalmente calizas excepto el lapislázuli, utilizado en pequeñas cantidades, e insertos en una base de mármol blanca se impone también en Florencia en la segunda mitad del siglo XvI, figurando varios en inventarios y en descripciones, como la realizada por Riccio de la galería de Niccolò Gaddi, citando entre ellos un ottangolo di marmo mischio ${ }^{23}$. Una característica de las las romanas, según se desprende de los inventarios y que se supone se extendió a toda la producción es que se recubrían con fundas de cuero pintadas y doradas y se destapaban solo en ocasiones determinadas ${ }^{24}$.

A proposito de la de Agostino Doria, Gonzalez Palacios opinaba que no debía excluirse a Génova como centro en el que pudieran haberse realizado taraceas de marmol de colores, pues trabajaron en la ciudad excelentes lapidarios ${ }^{25}$, dejando de este modo una puerta abierta a otros focos de producción. Parece que en el caso de las existentes en España, lo que sí es cierto y así se ha constatado repetidamente, es que muchos de estos tableros para bufetes, lo mismo que las esculturas y otros objetos de lujo, procedentes de Roma, llegaban a la Península vía Génova. Así se especificaba en una carta de Juan de Alarcón a Mateo Vázquez fechada en abril de 1587, en la que bajo el epígrafe Memoria de lo que se trajo de Roma... aparece una mesa de muchos y muy diversas piedras de jaspes y colores cortado y embutido, varias bolas de jaspe, pirámides de jaspes de muy buen color con su bola, un ara de jaspe, cuatro piezas pequeñas para sobrepapeles ${ }^{26}$.

Gonzalez Palacios atribuye una serie de dibujos para tableros a Giovanni Antonio Dosio, conservados en el Gabinete de Estampas de los Uffizi siguiendo a Morrogh ${ }^{27}$, aunque cada vez son más numerosas las publicaciones sobre diseños ornamentales de arquitectos italianos, que se conservan en diferentes bibliotecas del mundo, entre los que se incluyen jardines y tableros de commesso. Para el tablero que nos ocupa podrían haberse utilizado también los dibujos de Giovanni Vicenzo Casale (Florencia 1589-Coimbra 1591), fraile servita del que se conservan algunos en la

\footnotetext{
21 B. Jestaz: «La Decor Mobilier, la sculpture moderne et les objets d'art» Le Palais Farnese. Roma 1981. pp. 389-408. $81-97$

22 B. Jestaz: Op. cit., y Tuena: «I marmi commessi nel tardo Rinascimento romano» en Marmi Antichi. Roma 1990, pp.

${ }^{23}$ Agostino del Riccio: Istoria delle pietre. Edición a cargo de Raniero Gnoli y Attilia Sironi. V. A. Allemandi. Milán. 1996, p. 153. En los capítulos XLII-XLVI describe algunas calidades de alabastros, afirmando que en realidad pasaban de veinte clases, dedicando además otro epígrafe CXXVIII al alabastro oscuro que no diferencia exactamente, pudiendo ser de Palombara, a tartaruga o sardonico.

${ }^{24}$ B. Jestaz en su estudio sobre el Palacio Farnesio (véase nota 21), advirtió el paradójico uso del cuero dorado, decorado con lises, que cubría el gran tablero de la mesa Farnesio, a juego con otros paramentos., constatándose en el inventario 12, sin contar el de aquélla. Su uso está ya atestiguado en 1598 en la Villa Medicis: G. M. Andres The Villa Medici in Rome, 2, NB.York-London, 1976, p. 258, nota 693 y p. 262, nota 697. Perdura durante todo el siglo xvil como la del cardenal Mazarino «de ébano con piedras duras con su cubierta de cuero (1653)» o las del cardenal Paretti en Roma «con suo corame» o « con sua coperta di corame» (1655) Ibídem. Nota 34-35.

${ }^{25}$ Elena Parma: La scultura a Genova e in Liguria. II. 1988, incluye dentro de las consideradas genovesas un tavolino también octogonal fig.61, entre otras. Posiblemente esta vía tan utilzada sea la causa de que en los inventarios del siglo xvir, prácticamente todas las piezas de mármoles vengan denominadas como de marmol de Genova.

${ }^{26}$ I.V.D.J. Envío 54, fol. 285.

${ }_{27}$ Morrogh, A.: Disegni di architetti fiorentini. Florencia, 1985.
}

$A E A, \mathrm{LXXV}, 2002,299$, pp. 255 a 267 
Biblioteca Nacional de Madrid. Varios de ellos responden al tipo de tavolino ochavado, entre estudios de artesonados, de pavimentos de mármol y de tableros para mesas rectangulares, cuadrados y ochavados ${ }^{28}$. En uno de ellos aparecen notas explicativas alabas.. / cotognino/alabastro scuro /..fido roso /brocatello / ...tog...biancho e nero/ alabastro scuro / tognino cornice di marmo nero bellisimo / alabastro scuro /verte / canpo di nero ci sono con mess. questi troxes / alabastro scuro / canpo di brocatello / cotognino/ ornamento di lapis/alab'astro scuro / brocatello / brescia di tipoli / canpo di nero con questo fogliame. Junto al dibujo y con letra de Carderera: Invenciones para mesas de jaspes que se usan hacer en Roma

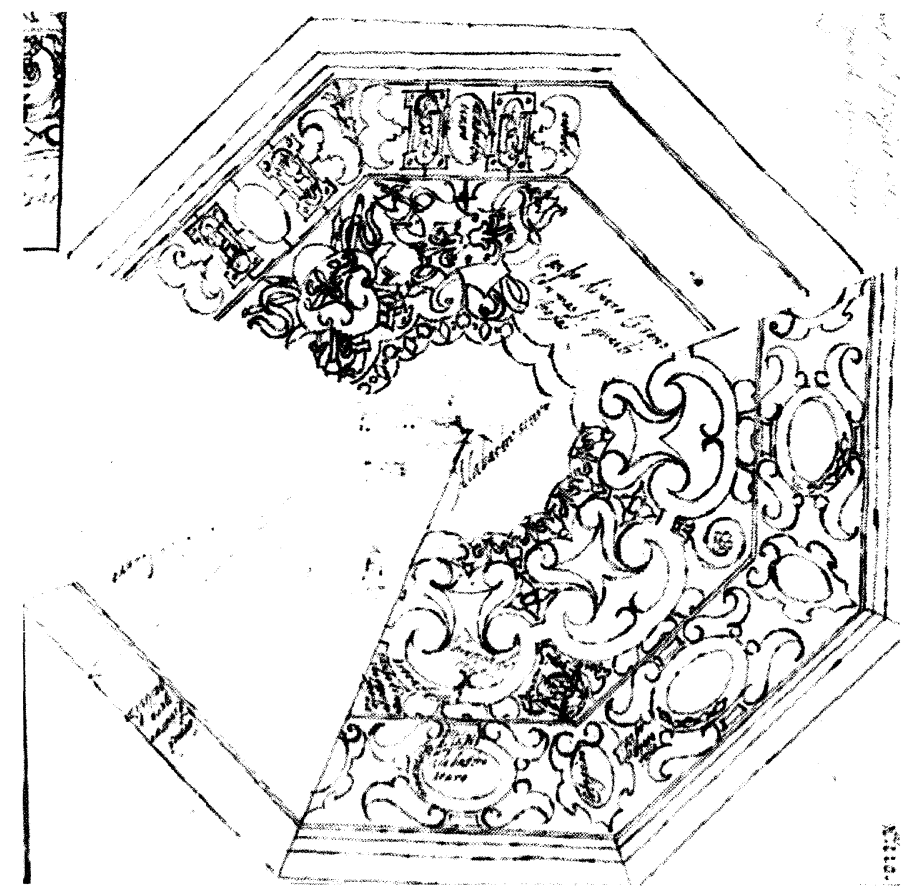

Fig. 11. G. V. Casale (1589-91): Diseño para mesa de jaspe . C-99. Madrid. Biblioteca Nacional. (fig. 11).

Son los dibujos descritos por Massai «sao rasgunhos de mezas de jaspes que se uzaô fazer em Roma e se fazen tanbem de madeira de cor» y que según él son similares a los folios 122 y 127p del mismo autor. Además de la descripción de los mármoles en el anverso sobre cada pieza en el reverso del $127 \mathrm{~b}$ figura: [pal]mo romano / con che sono misurate queste... ${ }^{29}$.

En estos dibujos se advierten cartelas a modo de panoplias como las que aparecen en la que comentamos de la abadía del Sacromonte, pero sobre todo como las que adornan la cenefa exterior de las del Museo de Artes Decorativas y de la de Lisboa (fig. 12).

En cambio un tercer dibujo a base de ortogonales muy marcadas (fig. 13) hay que ponerlo en relación con el el grupo de tableros realizados casi exclusivamente con piedras duras, como la regalada a Felipe II por el cardenal Alessandrino, hoy en el

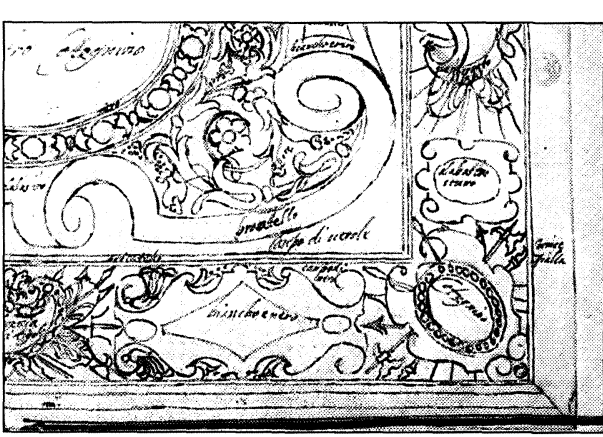

Fig. 12. G. V. Casale (1589-91): Diseño para mesa de jaspe. C-119. Madrid. Biblioteca Nacional. Museo del Prado, al otro extremo de la galería alta que la primera citada de la almoneda de D.Rodrigo Calderón y también sobre leones procedentes del Alcázar, la del florentino Museo degli Argenti, la que perteneció al duque de Westminster y que pasó a la colección Corsini de Nueva York, todas ellas realizadas en torno a 1585 (fig. 14) ${ }^{30}$.

\footnotetext{
${ }^{28}$ Marías, F. y Bustamante, A.: Dibujos de arquitectura y ornamentación de la Biblioteca Nacional. Siglos XVI y XVII. Madrid, 1991, t. I, C-99 y C-119.

${ }^{29}$ Ibidem, C-99, correspondiente al fol.110 del manuscrito.

30 Vease G. Palacios: Las colecciones... pp. 59-63.
} 


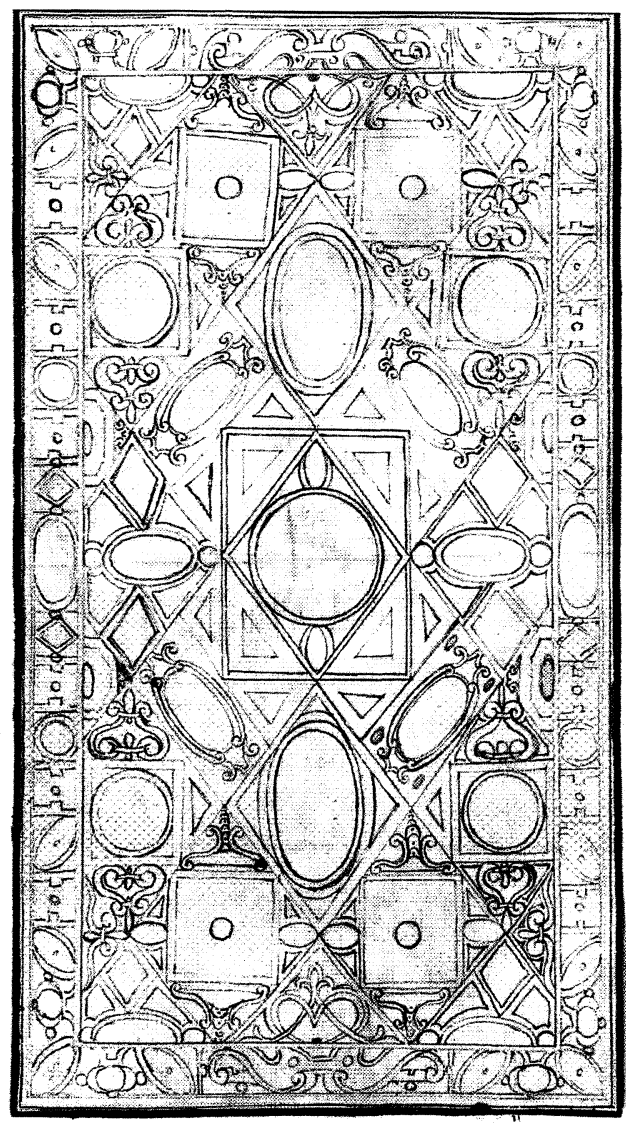

C. 114

Fig. 13. G. V. Casale (1589-91): Diseño para mesa de jaspe C-114. Madrid. Biblioteca Nacional.
Volviendo a lo que salió de Roma, resulta interesante completar los registros de las exportaciones citados por G. Palacios ${ }^{31}$ con los obtenidos por Jestaz a partir de las Diverse Cameralia del siglo XVI. En realidad, hasta Paulo III no fueron necesarias las licencias de exportación y su establecimiento creó cierto malestar, sobre todo entre los eclesiásticos franceses, ya que, como se ha dicho más arriba, es un hecho constatable el que la gran mayoría de las expediciones pasaban por las manos de los embajadores o los cardenales encargados de misiones diplomáticas y es a través de las valijas diplomáticas como salían de Roma ${ }^{32}$. A partir de 1551 estas licencias se relajaron y fue durante el papado de Pío V cuando el camarlengo Luigi Corraro (1577) promulgaba un Bannun super antiquitatibus Urbis por el que se prohibía «transportare vendere fora di Roma l'antiche statue et altri ornamenti degli diversa fati da li antichi», pero aún así abandonan Roma importantes convoyes de antigüedades destinadas a los grandes: al duque de Baviera, al Emperador, al cardenal d'Este, a Otto Truchess, cardenal de Augsburgo, al duque de Saboya o al de Mantua ${ }^{33}$. Las numerosas mesas realizadas a la moda utilizando mármoles antiguos, siguiendo los diseños entre los que se encuentran los realizados por los arquitectos reseñados y que en los documentos posteriores a 1571 aparecen como «modernas», apenas revis-

ten importancia en esos primeros envíos. En este comercio España no aparece directamente como país destinatario hasta 1554 , año en que se registran cuatro envíos, sin especificar ${ }^{34}$. No obstante, hay que resaltar que debido al intenso tráfico diplomático registrado en esos años, alguna de esta mesas modernas que salieron de Roma con esos destinos europeos, pueden ser las que aparecen más tarde en colecciones españolas. Este puede ser el caso de la mesa de piedra que embió a su Magestad el Cardenal de Augusta [Otto Truchess] ${ }^{35}$.

\footnotetext{
${ }^{31}$ Ibidem, p. 29.

${ }^{32}$ El 26 de octubre de 1554 se consigna una licencia para «Francisco Serason laico Neapolitanensi, qui ad Dei laudem capellam in partibus Hispaniarum construere intendit, extrahendi et in partibus Hispaniorum pro ejusdem capelle ornatu et structura convehendi sex scrinia lapillorum vulgo porfidi e mischi» (t. 181, fol. 62). Cfr. Jestaz: Op. cit., n. ${ }^{\circ} 35$.

El 27 de mayo de 1570 se concede permiso para sacar «sei casse dentrovi diversi pezzi di pietre mischie per ornamento di duae camini quali l'Ill.cardinale Delfino...fa condurre da Roma alla corte del Serenissimo Re Catholico per servitio del signor Enrico Gomez, maestro di Camera di S.M. Catholica, atteso che sono cose moderne» (t. 237, fol. 34). Cfr. Jestaz, n. ${ }^{\circ} 60$.

33 Ibidem. Envíos n. ${ }^{\text {ss }} 67,72,73,81,88,89,93$.

${ }^{34}$ Op. cit., p. 438

${ }_{35}$ Noticia que registra Sánchez Cantón en Bienes muebles... Felipe II, n. ${ }^{\circ} 4823$, al referirse en el cargo de tejidos a «una sobremesa de terciopelo carmesí con cenefa de los mismo, que en el medio tiene un escudo de las armas reales, bordada de cortaduras de tela de oro y torzales de oro y plata hilada de Milan y seda de matizes, con el Tussón con dos griphos a los lados del dicho escudo...que tiene vara y tres quartas en quadro, que sirve con la mesa de piedra que embio a su Magestad el cardenal de Augusta, tasada en 60 ducados-digo 20 duc. 7.500, cargada en el género de la almoneda, a pliego 394».
}

$A E A, \mathrm{LXXV}, 2002,299$, pp. 255 a 267 


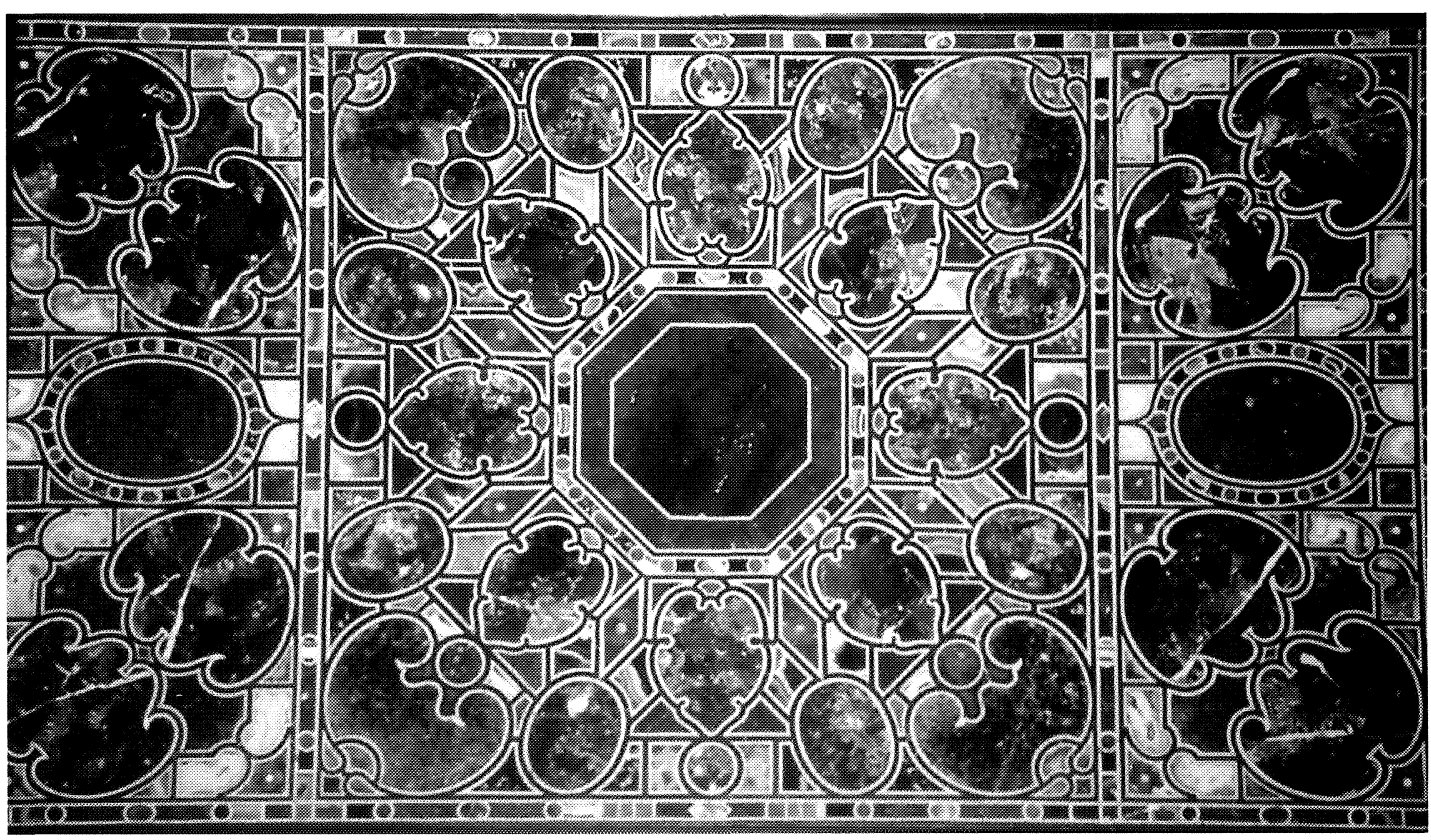

Fig. 14. Tablero de mesa de piedras duras. Roma 1580-1590. Nueva York. Colección Corsini.

En el extracto de licencias publicado, figuran en 1570 además dos que nos interesan especialmente para ilustrar este movimiento. De Roma en el plazo de un mes salieron entre otras piezas seis «tavole intarsiate de diverse pietre, una tavola di marmo commessa con alcune sorti di marmo mischi....da Roma in Sicilia per servigio del signor Ottavio Spinola, atteso che sono cose moderne» (t. 237, fol.40). El 7 de mayo de 1571 «lasciate pasare una tavola col suo piede di marmol mischio lavorato, moderna, quale l'ostensor delle presente conduce a Napoli per servitio del signor Jo.Battista Figliomarino, conte della reca, napolitano» (t. 245, fol.150) ${ }^{36}$. En dos de marzo de 1571 aparecen entre otras piezas «due tavolini picoli di diverse pietre...quali il signor $\mathrm{Fe}$ rrante Torres manda da Roma a Napoli per servitio del.vice-re di napoli, attesso che sono cose moderne» (t. 245, fol.105 verso) ${ }^{37}$. Gonzalez Palacios, basándose en los documentos publicados por Antonino Bertolotti, extracta los relacionados con las licencias de exportación desde 1587, confirmando el que las licencias para Nápoles constituyen una via interesante para identificar los objetos destinados a España. El 8 de agosto de 1577 el virrey de Nápoles envía a su residencia oficial una mesa de mármol veteado. El 26 de abril de 1583, don Gonzalo Ponce de León, camarero secreto del papa, manda al virrey una mesa y en 1585 el correo mayor de Su Majestad Católica en el Reino de Nápoles, con un tablero de marmol embutido. Otro más «lavorato di alcune pietre» sale el 3 de mayo de 1592. El 6 de mayo de 1619, dos lapidarios envían «tres mesas modernas de mármol taraceado» aunque no se especifica a quien ${ }^{38}$. Mientras tanto, la producción florentina utiliza cauces similares, en algunos casos bien documentadas, como la desgraciadamente perdida que fue enviada por el Gran Duque Fernando en 1604 para la condesa de Lemos a través de D.Pedro de Toledo y que se sabía llegó a Alicante ${ }^{39}$. Como se observa a partir de es-

\footnotetext{
${ }^{36}$ Ibidem, n. ${ }^{\circ} 92$.

${ }^{37}$ Ibidem, n. ${ }^{\circ} 87$.

${ }^{38}$ Bertolotti: «Esportazioni di oggetti di Belle Arti da Roma. Regno di Napoli» y «Esportazioni di oggetti di Belle Arti da Roma in Spagna» en Archivio Storico... della città e provincia di Roma, 1877, II fasc. I, 21-40 y 1880, IV, fasc. III, 281285, respectivamente, cfr. Gonzalez Palacios, 2001, 29.

${ }^{39}$ ASF Mediceo dell Principatto 5080, fol. 1257v. Cfr. G. Palacios 2001, p. 23 y nota 20, efectuándose pagos por ella en 1602 y 1603 .
}

AEA, LXXV, 2002, 299, pp. 255 a 267 
tas notas, además de los citados envíos a través de Genova, son numerosos los que utilizan la via napolitana desde 1577 a 1592, por quedarnos dentro de los límites del siglo XVI.

Como novedad respecto a posibles artífices, que se puedan añadir a los ya citados por Gonzalez Palacios, podemos citar las notas que Antonia Boström publica junto con la descripción que Ulisse Aldrovandi, el científico boloñés, hizo en 1586 de algunas piezas de la colección de Giovan Vettorio Soderini, quien en 1586 tenía una mesa octogonal con mil quinientas piezas. Asimismo destaca que Soderini empleó a Giulio Basimelli para realizar obra de comesso y parece que coleccionó y vendió mármoles y piedras, según se desprende de los inventarios de su casa y de la venta de su colección ${ }^{40}$.

De la llegada de nuestra mesa a la Abadía granadina del Sacromonte, no se ha hallado ningún documento de la época en que aparezca citada. Su presencia allí, sin embargo, no es extraña, dada la importancia y las relaciones del fundador, el entonces arzobispo de Granada don Pedro Castro Cabeza de Vaca y Quiñones, quien erigió la abadía para dar culto a las cenizas de San Cecilio y de otros mártires aparecidos en la colina de Valparaíso. Don Pedro, perteneciente a una familia que se mantuvo siempre al servicio de los intereses de la monarquía, fue nombrado sucesivamente virrey de Peru y Cuzco, Presidente del Consejo de Castilla, por indicación de Francisco de Borja a Felipe II. Fue elevado a la sede granadina en 1590, tras ser visitador, oidor y presidente sucesivamente de la Capilla Real y de la Real Chancilleria de Granada de 1563 a 1583. Vinculado estrechamente a la Compañía de Jesús, prestó un decidido apoyo a la beatificación de San Ignacio. Los documentos del Archivo del Sacromonte muestran un contacto ininterrumpido entre él y Felipe II, por lo que se le puede considerar como uno de los más importantes ejecutores de las decisiones político-religiosas de la monarquía. Siguiendo su biografía se advierte un interés extremo por la búsqueda del decoro, por utilizar un término de la época, para los edificios religiosos de su diócesis.

Dentro de sus iniciativas culturales, en 1591 ornamenta todas las iglesias de su Arzobispado, empieza el crucero de la Catedral y reforma la Universidad y el Colegio Real granadinos.

El Sacromonte representó el esfuerzo de su iniciativa al considerar como determinantes los hallazgos de las reliquias en 1588 y 1595 , con la construcción de una abadía y colegio, haciendo patente el sentir de la actividad intelectual de finales del siglo XVI ${ }^{41}$.

Entre las noticias dadas por Royo Campo sobre don Pedro de Castro ${ }^{42}$ se cita el papel de la duquesa de Sessa en el reconocimiento de las reliquias ${ }^{43}$, la continua correspondencia de arzobispo con Felipe II y los breves de Clemente VIII en la calificación canónica de las reliquias, facultad concedida a los prelados por el Concilio de Trento y autentificadas por él en 1607. La figura y la obra de don Pedro de Castro fueron objeto de admiración y reconocimiento a lo largo del tiempo. En el siglo xviII Diego Nicolás Heredia Barnuevo escribió el Místico Ramillete. Vida de don Pedro de Castro, fundador del Sacromonte. En la introducción se insistía en la sobriedad espartana, en la extrema modestia del arzobispo, quien nunca admitió dádivas ni

\footnotetext{
${ }^{40}$ Aspects of the collecting and display of sculpture in Florence and Rome c. 1450-c. 1595. Tesis doctoral depositada en el Courtauld Institute of Art de Londres, consultada por gentil indicación de la autora.

${ }^{41}$ I. Henares Cuéllar y M. J. Hagerthy: «La significación de la fundación en la cultura granadina de transición al siglo xvir en la Abadia del Sacromonte. Exposición artística y Documental. Etudios sobre su significación y orígenes. Universidad de Granada 1974 p.41-45.

${ }^{42}$ Zótico Royo Campo: El insigne colegio seminario del Sacro-Monte y la Universidad de Granada. Granada 1951, p. 42 .

${ }^{43} \mathrm{Su}$ figura queda recogida incluso en los grabados que Francisco Heylan realizó como testimonio de los hallazgos. Asimismo resulta curioso que la composición que este mismo grabador realizó para la Historia eclesíastica de Antolínez de Burgos en 1611 represetando los «Martirios de Ugíjar», sea extraordinariamente similar a la realizada por el grabador Antonio Spano en el frente de un escritorio napolitano de colección privada madrileña. Véase para éste, Aguiló: «La exaltación de un reino: Nápoles y el mobiliario de lujo a la vuelta del siglo xvı», Archivo Español de Arte, 1992, n. ${ }^{\circ} 258$, pp. 179-199.
}

AEA, LXXV, 2002, 299, pp. 255 a 267 
regalos. Repetidamente se hace hincapié en que incluso, en los casos en que dispuso dotar las iglesias de retablos, imágenes u objetos litúrgicos, la preocupación de Castro parece haber estado más en la línea de introducir los elementos de culto necesarios, que en la de valorar la dimensión artística de los objetos. Era en definitiva un reflejo de su personalidad, pues nunca permitió que en sus habitaciones hubiera cuadros ni cualquier otro objeto artístico lujoso. Su unica aportación fue el complejo sacromontano, que, pese a su indiscutible relevancia se considera una obra fallida respecto del grandioso plan ideado por él ${ }^{44}$.

Esta austeridad se hace patente enn el inventario registrado de los bienes donados por el arzobispo a la Abadía en el que se cita una tapicería de Flandes con la $\mathrm{H}^{\text {a }}$ de Ezequiel, cinco sitiales y unas sillas rasas para los sitiales, tres imágenes guarnecidas de ébano y plata las cantoneras y un sillón con sitial rojo de terciopelo, que es el que hoy se conserva ${ }^{45}$. Sin embargo tanto D. Manuel Gomez Moreno como Gallego Burín constatan la presencia en la sacristía de «una mesa de cálices con incrustaciones embutidas de mármol» ${ }^{46}$, que es la que aquí publicamos. Repasando el Ramillete, se encuentran algunas noticias de viajes entre Granada y Roma que pudieran haber servido de correo. Por ejemplo, el 2 de agosto de 1616 volvieron a Sevilla desde Roma, dos colegiales del Sacromonte, favorecidos en la Santa Sede con la concesión de las Bulas de la Abadía, la concesión de la Gracia de un jubileo, gracias, favores y privilegios para la Colegiata ${ }^{47}$, aunque lo más posible que su presencia allí se deba a una entrada posterior a la etapa del arzobispo fundador, dado que no se contempla en el inventario citado ni ha pasado al museo creado al efecto, permaneciendo hasta hoy como un elemento más del mobiliario litúrgico de la sacristía.

\footnotetext{
${ }^{44}$ Estudio preliminar y álbum iconográfico de Manuel Barrios Aguilera. Granada, 1998, p. XIX.

${ }^{45} \mathrm{M}^{\mathrm{a}}{ }^{2}$ Luisa García Valverde: «La donación del arzobispo don Pedro de Castro al Sacromonte: el inventario de sus bienes», Cuadernos de Arte. Universidad de Granada, 27, 1996, pp. 283-295. A.H.P. Granada. P. Rodrigo Dávila n. 367 (1602) fol. 123r-146r. Para Gallego Burín este último está adornado con bordados toledanos cfr. Guía Artística e Histórica de Granada. Ed. 1991 de Fco. Javier Gallego Roca, p. 363.

46 Guía de Granada, 1892, p. 473.

${ }^{47}$ Ramillete, ed. cit., p. 468.
} 